\title{
NARRAR É GLOSAR, VIVER É NARRAR
}

Eneida Maria de Souza

(UFMG/CNPq)

\section{RESUMO}

O presente artigo analisa a colaboração de Dirce Côrtes Riedel para a recepção crítica de Guimarães Rosa, levando em conta a publicação de ensaios e livros dedicados à obra do autor. Acrescenta ainda o papel da intelectual na formação de professores e pesquisadores de várias universidades do país.

PALAVRAS-CHAVE: Recepção; crítica; universidade.

De interpretação em interpretação, chegamos ao texto sem fim, para cuja leitura Roland Barthes convoca um leitor que movimente o sentido que escorrega, recupera-se e avança. Porque interpretar o texto não é dar-lhe um sentido mais ou menos instituído, mais ou menos livre. Não se trata de interpretações liberais, mas de apreciar de que plural o texto é constituído, já que o "eu" que se aproxima do texto é já em si mesmo uma pluralidade de outros textos, de códigos infinitos ou perdidos.

Dirce Côrtes Riedel

A convivência acadêmica e pessoal com Dirce Côrtes Riedel desde os anos de 1970 a meados de 1990 não poderá ser definida de modo simples ou apressado. O convívio com a professora, crítica e amiga, durante esse período, foi alimentado pelas lições de literatura e vida e pelo entusiasmo constante em relação às novidades teóricas e às predileções literárias. Guimarães Rosa, ao lado de Machado de Assis, foi uma de suas eleições mais constantes, paixão crítica transmitida em sala de aula e divulgada em artigos e trabalhos dedicados ao escritor. A estreita ligação entre prática profissional e experiência moldou a imagem da intelectual 
nos seus vários aspectos, uma vez que o exercício da crítica literária se configurava parte integrante de um estilo de vida. Raramente encontram -se no espaço crítico e acadêmico pessoas empenhadas na realização da difícil simbiose entre teoria, literatura e vida, o que responde pela atuação desprendida de quem assim elege o magistério como forma de compromisso com os ideais de cidadania e de ética profissional. Nesse sentido, o lugar ocupado por Dirce no meio universitário e intelectual das últimas décadas do século 20 não se restringe à atividade de crítica literária, mas abrange outras de igual ou maior importância, como a generosidade intelectual e a abertura para amplos campos do saber.

O legado de sua lição como incentivadora de novos pesquisadores e de projetos institucionais se estampa na criação pela UERJ da Casa de Leitura Dirce Côrtes Riedel, onde se encontra o acervo aberto ao público e a possibilidade de realização de atividades relativas ao aprimoramento de suas escolhas literárias, com a oferta de cursos e conferências. A oportunidade de reverenciar sua obra por meio da consulta a manuscritos, livros de sua autoria, esboços de pesquisas e à biblioteca particular, permite maior conhecimento, divulgação e revitalização de sua imagem pública como eminente figura do sistema educacional brasileiro.

Ao aceitar o convite para discorrer sobre sua atuação crítica em torno da obra de Guimarães Rosa, não poderei limitar-me, portanto, à sua produção escrita, por reconhecer o papel que exerceu como professora de literatura brasileira em diversas universidades brasileiras, incluindo aí a UERJ, a PUC-Rio e a UFMG. Como professora visitante ou efetiva, Dirce teve o mérito de introduzir uma abordagem singular aos textos de Rosa, por meio da leitura centrada nos mínimos detalhes frente à linguagem tão complexa e diferenciada do autor. Esta atenção ao exercício minucioso dos procedimentos de linguagem é tributária de sua formação estilística, responsável pelo perfil de grande parte da crítica de sua época. A entrada fecunda do estruturalismo e do pós-estruturalismo no ambiente acadêmico da PUC nos anos de 1970 teve adesões da maioria dos docentes, destacando-se aí Luiz Costa Lima, Affonso Romano de Sant'Anna, Silviano Santiago e a própria Dirce. A escolha de uma linha teórica ou a preferência por este ou aquele pensador era distinta entre eles, razão pela qual se torna difícil estabelecer um parâmetro único para a recepção estruturalista/pós -estruturalista desse momento nos programas de pós-graduação.

A posição da professora quanto a essas escolhas, marcada pela ausência de radicalismos ou fechamentos de teor ideológico, concorreu para 
a leitura de textos que se tornaram clássicos, como os de Gilles Deleuze, Mikhail Bakhtin, Roland Barthes, entre outros. A este aparato teórico incorporava-se a interpretação das artimanhas de linguagem dos autores escolhidos, em concordância ao pensamento igualmente filosófico/literário de Rosa e de Machado. $\mathrm{O}$ interesse pela leitura dos procedimentos literários na sua integridade conseguiu reunir a boa tradição estilística às novas propostas de abordagem estrutural. A essa reunião de ordem metodológica foi anexada a ampliação do conceito de texto, com o intuito de instaurar elos entre o estudo da linguagem, sua contextualização e as variadas associações interdisciplinares.

Os programas ministrados por Dirce no período de 1972 a 1974, referentes ao mestrado por mim cursado no Instituto de Letras da PUC- Rio, versando sobre temas os mais diversos - a literatura surrealista, obras de Guimarães Rosa (Tutameia e Primeiras estórias), A invenção de Orfeu, de Jorge de Lima, poemas de Murilo Mendes - privilegiavam a leitura pontual da obra de determinado autor. Grande sertão: veredas atuava como leitmotiv da reflexão sobre Rosa, demonstrada na atividade acadêmica e na redação dos ensaios. Com enfoque na composição da estrutura poética e narrativa dos objetos literários, sua investigação conduzia ao exercício meticuloso de análise textual. A crítica literária francesa fornecia também rico material de apoio às pesquisas sobre o movimento surrealista, as regras funcionais da narrativa e procedimentos estruturais de composição. Destacavam-se entre eles Julia Kristeva, Tzvetan Todorov, Philippe Sollers, Michel Zeraffa, Roland Barthes, representantes da vertente estruturalista da crítica e leitura quase obrigatória no meio acadêmico do momento. Essa bibliografia, lida por nós nas edições originais, nos era permitido adquiri-la na livraria Leonardo da Vinci, reduto da cultura francesa, ponto obrigatório para conversas e aquisição das últimas novidades literárias e teóricas.

A abordagem crítica de Dirce revela-se dotada de rigor e sofisticação, ao conseguir reunir ingredientes da teoria literária e preceitos filosóficos, relacionar poética e mito, raciocínio filosófico e invenção, enunciado narrativo e conhecimento. A conjunção bem sucedida entre esses discursos foi tributária da apropriação do pensamento deleuziano sobre o paradoxo, do mecanismo repetitivo e diferenciado das ações e do questionamento de verdades regidas pelo senso comum. Diferença e repetição, Lógica do sentido, Proust e os signos, entre outros títulos do autor, destacavam-se como referência para a articulação engenhosa dos 
conceitos a serem utilizados na crítica e como princípios norteadores do jogo discursivo.

Exemplos retirados de textos de Guimarães Rosa constituíam - e ainda constituem - saída para a interpretação da literatura na sua natureza ambivalente, desprovida de soluções marcadas pela polarização do binarismo. O estatuto cambiante das verdades estabelecidas, o ir e vir das certezas, a sensação de angústia vivida pelo sujeito frente aos não-saberes e às dúvidas resultavam na indecidível operação entre teoria e ficção, filosofia e literatura.O humor, protocolo de leitura derivado da reflexão deleuziana, exerce a função de norteador das ações e de argumento para esclarecer a enunciação literária de Rosa,na qual se substitui a relação conciliadora entre os termos pela convivência conflituosa entre eles. Exemplos da fórmula empregada pelo escritor ao longo de seu texto registram a incerteza e a "diferença semelhante" do processo construtivo do discurso, pela imposição de sentimentos de dúvida e indecisão frente aos acontecimentos: "É e não é". O senhor ache ou não ache. Tudo é e não é; “ainda é... já não é”, ou nas referências a Deus ou ao Diabo: "Deus existe mesmo quando não há";"o que não há está solto". Glosando a fala de Rosa, a arguta leitora reelabora teoricamente o impasse e endossa a contradição na maneira de lidar com o aspecto ambivalente da obra literária e de sua recepção.Seria este um dos legados da ensaísta ao longo de sua produção crítica, estampado em livros ou na comunicação oral: o pensamento inquieto e a vigilância quanto aos princípios regidos pelo senso-comum e pelas armadilhas da enunciação literária.

$\mathrm{Na}$ esteira de Mikhail Bakhtin, duas obras muito estudadas na época - Problemas da poética de Dostoievski e A cultura popular na Idade Média e no Renascimento - o contexto de François Rabelais - apresentavam novas visões sobre a ligação entre literatura e ritual carnavalesco, afirmando a importância do elemento popular e dos gêneros considerados "inferiores" e impulsionando o conhecimento do universo imaginativo do sertão de Rosa, entre outras obras. O aspecto construtivista da linguagem se completava pela observância crítica face às questões sociais e culturais, por entender a ensaísta ser limitada a interpretação da obra apenas pelo viés literário, valorizando-a na sua autonomia. Sob este olhar crítico,a narrativa rosiana é a via principal de reconstituição do universo literário, povoado de atores e interlocutores. Tem o cuidado ainda de distinguir vários tipos de narradores no interior da obra, a distância entre vozes populares, enunciados enganosos e enunciações reveladoras. 
A reversibilidade de situações resultante da inversão de valores do rito carnavalesco, a ruptura com as normas e a precariedade da luta entre bem e mal encontravam eco na própria concepção de Rosa do aspecto inusitado e intempestivo do espaço do sertão. As peripécias das personagens, entregues ao acaso e ao desejo de mudanças, se resolviam à luz de happenings, de acontecimentos inesperados e de respostas que contrariavam o status quo. Formulações originais em relação ao conceito de fantástico se apoiam nessa reflexão, a ponto de ser entendido como fruto do "inevitável acaso". Trata-se de uma das muitas acepções conferidas ao termo, ao ser considerado como efeito de narrativa, construído segundo as regras por ela impostas.

Na abordagem dos contos de Tutameia, realizada durante curso ministrado sobre o autor, Dirce privilegiava os recursos literários do humor na construção da narrativa e inaugurava, à luz das teorias de Deleuze, interpretação original do tema do destino. Pela incidência do humor, o sentido trágico do destino se desfaz, causado pelo acontecimento imprevisto e desestruturador. O desenrolar das ações, motivado por personagens que fugiam da normalidade, como velhos, crianças e loucos, conferia legibilidade ao acaso e provocava a inversão de valores consagrados pelos ditames da racionalidade. Na definição da autora, essa ação intempestiva, criada no próprio espaço textual, seria um espaço que transborda, "transvive uma suprarrealidade, numa realidade total - o 'mil maravilhoso'. Um happening!":

No happening do conto "Presepe", de Tutameia, a verdade do Natal se torna visível na produção do sentido poético, através do "desarranjo do juízo de Tio Bola, o 'caduco maluco' que quis 'ver visões'. Não parecia provável aquele presepe vivo, burrinho e vaquinha, o imbecil Anjão e a cozinheira Nhota, no curral, contemplando Tio Bola no cocho, em companhia de Deus e das estrelas".

Entre as diversas qualidades encontradas na figura da educadora, não é possível esquecer as reuniões mantidas em sua residência, com vistas à leitura e discussão de textos de autores de interesse para a crítica naquele momento, como Lévi-Strauss, Wittgenstein, Freud. Congregar pessoas e contribuir para a formação de uma comunidade pensante respondiam pelo sonho por ela acalentado durante sua vida dedicada à pesquisa e ao magistério. Sem a exigência do protocolo comum ao ambiente acadêmico, as relações e afinidades literárias iam se formando e se convertendo em amizades novas, dentre as quais muitas ainda permanecem. 
A convivência com a jovialidade da mestra nos fazia sentir capazes de adquirir a sabedoria que dela emanava. As palavras de Rosa, "Mestre não é quem sempre ensina, mas quem de repente aprende", servem para definir a ausência de hierarquia que sempre a caracterizou, servindo de exemplo para todos nós. Não resta dúvida de que as mudanças de toda ordem verificadas na década de 1970 atuavam como abertura de caminhos em direção à dissolução de barreiras disciplinares e de comportamentos vinculados às propostas conservadoras e exclusivistas. Estávamos vivendo momentos de euforia no âmbito da revolução das ideias, obrigando-nos, contraditoriamente, a permanecer acuados frente às restrições causadas pelo regime ditatorial. As leituras convergiam para o debate dessas ideias, à medida que seria inconcebível separar as teorias dos acontecimentos e das ações repressivas dirigidas contra a liberdade de expressão.

Muito se comentava na ocasião a respeito da relação entre a abordagem estruturalista - a utilização de modelos lógicos de raciocínio e de critérios racionalistas - e o encobrimento da denúncia social e política como prova de alienação de seus seguidores. Neste particular, ignorava-se - e até hoje a história das ideias ignora - a ruptura propiciada pelas teorias desconstrutoras levadas a termo por eminentes pensadores, a maior parte de origem francesa. Comete erros de interpretação desses movimentos quem ainda se pauta pela acusação da metodologia de análise empregada, esquecendo-se de apontar a transformação operada no âmbito das ciências humanas quanto à ruptura do positivismo histórico e do humanismo, correntes de pensamento que vigoravam até então. No campo da crítica literária, antropológica, psicanalítica e outras, instaurou-se o procedimento analítico com base em critérios formalistas, com mudanças significativas quanto ao rompimento com a paráfrase, o biografismo, a intencionalidade e a descrição naturalista dos fatos. A desconfiança frente aos sistemas de poder e à imposição de verdades discursivas era moeda corrente nas discussões teóricas e nas interpretações de textos, não se desvinculando do compromisso assumido por grande parcela da crítica.

****

Na releitura da contribuição de Dirce à obra de Guimarães Rosa, o leitor contemporâneo poderia se perguntar sobre a reduzida publicação dos artigos em livro, tendo em vista a proliferação de estudos sobre o autor na atualidade, graças à facilidade de editoração, inexistente em épocas anteriores. Somem-se a isso exigências acadêmicas para a for- 
mação de currículo do profíssional, ao lado do gesto nem tão comedido de se publicar a qualquer custo. A título de curiosidade, a primeira tese acadêmica sobre o autor é de sua autoria, defendida em 1966 por ocasião do concurso para a cátedra de Literatura Brasileira na Universidade do Estado da Guanabara, intitulada Aspectos da imagística de Guimarães Rosa. Embora não tenha sido publicada em livro, encontra ressonâncias nos artigos escritos posteriormente. Em 1961, com O mundo sonoro de Guimarães Rosa, já havia escolhido o autor como tema da tese no concurso para a cátedra de Português e Literatura do Instituto de Educação do Rio de Janeiro, sem nunca ter sido estampada em livro, por deliberada decisão da autora. Explica-se ainda o pouco empenho das instituições em divulgar trabalhos desta natureza, por terem as teses tratamento restrito ao ambiente acadêmico, ao lado da precariedade editorial do momento.

A revisita aos ensaios sobre Rosa, publicados de forma esparsa em jornais e periódicos especializados, além dos livros - Meias-verdades no romance, de 1980, com artigos sobre o escritor e Viver literatura, coletânea organizada por Ana Cláudia Viegas -, comprova a atualidade e a excelência desses escritos e a necessidade de se fazer justiça ao lugar da ensaísta na tradição da crítica rosiana brasileira. A compreensão do universo poético do autor teve como argumento principal a exploração do valor conferido à linguagem e à complexa teia narrativa de sua obra. Optou-se pela escolha do elemento popular como gerador de múltiplas vias interpretativas, seja na ênfase aos detentores de mudanças no sistema social, como loucos, crianças, seja na percepção do poético, não circunscrito à camada letrada, mas resultante da articulação do erudito com o popular. Entre os vários temas abordados por Dirce nos ensaios críticos distinguem-se o aspecto metalinguístico das estórias; a produção de narradores que se debatem entre vozes dissonantes da comunidade; $o$ poder indiciador dos nomes próprios para a compreensão do desenrolar do enredo; a defasagem entre enunciado e enunciação, em que a produção textual funciona como ato e atividade poética. A cuidadosa análise do enunciado literário servia de base para a contextualização da crítica rosiana, ao se considerar as implicações sociais e políticas presentes nas propostas revolucionárias, tanto no âmbito da construção da linguagem quanto da narrativa.

Por reconhecer Guimarães Rosa como representante privilegiado do cânone literário de seu tempo, a ensaísta reitera o grau de estilização da narrativa de Grande sertão: veredas, ao assinalar o poder da palavra dian- 
te do fato. Com esta afirmativa, restringe-se a oposição entre realidade e ficção, pelo gesto da memória narrativa em criar/destruir lendas e mitos, convertendo-se em "realidade pensada". Ressalta, em outros contos, a figura do "narrador impessoal", "o contador de estórias fantasiadas de história, narrativas já contadas, conferidas, fábulas postas em ata." O gesto de contar estórias teria o estatuto do texto de segunda mão,ao se apropriar da fala alheia, distanciar-se do fato e endossar o mundo fabuloso da lenda. Na excelente abordagem da novela "Buriti", associa o ato de narrar à glosa, focalizando-se na personagem de Miguel enquanto "ouvinte da narrativa de Gualberto". A transmissão de mensagens mal entendidas, o esforço em reconhecer a fala do outro se justificam pelas meias-palavras e pelo complexo exercício de interpretação. Filia-se ainda à recepção poética, quando a ensaísta tenta desvendar o mistério da poesia engendrada pela glosa de mensagens entre personagens: "Narrar é fornecer um mote; ler é glosar. Mas o texto também pode ser uma glosa de uma leitura que seja, por sua vez, a glosa de outra leitura... do real da estória."

A percepção do estatuto ficcional da realidade antecipa teorizações recentes centradas na articulação entre real/ficção, em torno da qual Jacques Rancière, em A partilha do sensível, conclui: "A poesia não tem contas a prestar quanto à ' verdade' daquilo que diz, porque, em seu princípio, não é feita de imagens ou enunciados, mas de ficções, isto é, de coordenação entre atos. (...) $\mathrm{O}$ real precisa ser ficcionado para ser pensado". $\mathrm{O}$ aspecto fabuloso da fala rememorativa reitera a astúcia da enunciação rosiana, entendida pela ensaísta como o impasse entre as incertezas do sim e os volteios do não:

A força da palavra destrói o fato, que passa a não existir, obstruído pela fala do poeta: 'Não escrevo, não falo! - para assim não ser; não foi, não é, não fica sendo! Diadorim...' A realidade é construída pela palavra, que apaga a realidade vivida para fazer a realidade pensada. O narrador não toma conhecimento da morte, continuando a viver o mágico encantamento de Diadorim. Uma experiência que não se separa dos mitos e lendas dos Gerais, 'nas beiras e matas escuras e águas todas do Urucuia'.

Na lúcida interpretação dos discursos das personagens, o texto de Dirce ganha em atualidade, se for comparado aos demais especialistas da obra em questão. Embora os temas tratados por seus pares respondessem pelo enfoque literário, histórico ou político, o mérito de sua proposta residia na configuração mitopoética e filosófica de Rosa. Incentivada pela leitura praticada por vários teóricos, percebe-se que a afinidade com a 
abordagem filosófica de Benedito Nunes sobre o autor, resultante de sua formação, permite a integração da ensaísta nesta linhagem crítica. O exercício comparativo e interdisciplinar constitui uma de suas mais pontuais escolhas analíticas, por incentivar a abertura da crítica aos inúmeros campos do saber, incluindo aí teorias e literaturas estrangeiras. Sem preconizar o estatuto local e isolado das manifestações artísticas, Dirce sempre se comportou de modo avançado quanto à recepção de teorias e ao confronto comparativo entre autores de várias nacionalidades. Os exemplos são vários, destacando-se o estudo contrastivo sobre o narrador/artista em Rosa e Lautréamont, no artigo incluído em Meias-verdades no romance, "O poeta em ação", em que assinala as semelhanças e diferenças entre a construção narrativa de Grande sertão: veredas e Cantos de Maldoror.

Por se tratar de um autor de reconhecida amplitude intertextual de sua obra, pelas inserções de literaturas estrangeiras e do imaginário mítico e lendário do país, as relações comparativas exigem do crítico de Rosa abordagem correta e atenção aos diálogos entre culturas e autores. Lautréamont, Marcel Proust, Goethe, Machado, Alejo Carpentier, Georg Lukács, Roland Barthes, Walter Benjamin, Gilles Deleuze, Antonio Candido, Roberto Schwartz, Silviano Santiago, Luiz Costa Lima, entre outros, compõem o quadro referencial da ensaísta na sua produção crítica, conferindo ao trabalho analítico a possibilidade de pensar a cultura brasileira em termos de igualdade e diferença face às demais manifestações artísticas mundiais. A intertextualidade, conceito extraído de Julia Kristeva, via Mikhail Bakhtin, possibilitou a quebra de critérios relativos à prisão do pensamento periférico a questões de origem e lugar fixo onde as ideias poderiam ter nascido. Como elucidação desta proposta, cite-se a passagem do ensaio da autoria de Dirce, publicado na década de 1990, em que refuta concepções da crítica comparativa tradicional, pautadas pela decifração de fontes e influências, pela defesa do espaço textual periférico responsável pela "desleitura-réplica" da herança europeia:

Porque o discurso literário não é a tematização de determinadas fontes e de determinadas maneiras de ver o mundo, que o informem e o conformem previamente, a subversão da ordem causalista, tão grata ao positivismo, contribuiu para reformulações do estudo de fontes e de influências, passando o texto a ser entendido como assimilação-transformação, desleitura-réplica de textos anteriores.

O papel subversivo da obra de Rosa manifesta-se no interior das instituições, da família ou da comunidade, pela ruptura de verdades ofi- 
ciais e preconceituosas, convergindo para a releitura de tradições e da necessidade em produzir novas saídas. $\mathrm{Na}$ abordagem de alguns contos, como "Pirlimpsiquice", "O espelho", "Presepe', "Os chapéus transeuntes", incluídos em livros distintos, questionam-se valores implícitos na constituição da ordem escolar e no discurso defendido pela visão adulta; a repetição de ritos estereotipados pelo senso comum, como o Natal; a decepção do sujeito diante da imagem perdida no espelho ou o aspecto residual de objetos simbólicos, como relógios, urinóis e chapéus, representantes da tradição patriarcal e burguesa. A denúncia social estaria implícita na desorganização dos rituais cotidianos, na desconfiança dos jovens diante de valores não mais sustentados pelas novas gerações. No texto "Ainda é...já não é", Dirce destaca o conflito entre velhos e jovens, na desmistificação da tradição que aos poucos é abalada pelo rompimento com os vícios da retórica burguesa. A atenção aos símbolos reveladores da decadência familiar se enquadra, ao olhar da analista, à perspectiva alegórica, demonstrando fina percepção e crítica social. Walter Benjamin, teórico da alegoria barroca e autor atualmente consagrado no meio intelectual, já figurava como interlocutor de texto publicado no início dos anos de 1980:

A importante nobreza impertigada, em que também o Ratapulgo se apoia, é fechada aos "evidentes exemplos do invisível". Esta não percepção para a poesia faz questão de "história e espaço". Nesta história e neste espaço, a arte dos urinóis, de faiança, de porcelana ou opalina, impõe-se ao narrador, cuja dicção se esmera na sua apresentação. O urinol, como signo, se faz imagem iterativa e degradada pela alegoria, no sentido que lhe dá W. Benjamin. É o valioso objeto que contém os dejetos do poder, que o criado conduz com ostentação e que compõem a sua nenhuma individualidade. No mesmo plano de importância está o chapéu - guardião do que contém os detritos ideológicos do poder.

O questionamento de valores esclerosados da sociedade é sinal relevante de denúncia social, mesmo que a dicção rosiana inscreva-se, segundo a ensaísta, de forma alegórica e sutil. Evidencia-se aí sua lúcida percepção, ao defender a posição de Guimarães Rosa e de Machado frente aos movimentos sociais e à crítica cultural, surgidos nos anos de 1980, conhecidos como "politicamente corretos", pela exigência de compromisso da literatura com as causas políticas. Em "Interpretação e ficção: interpretação de interpretações e outras interpretações" discorda, à luz da reflexão de Lukács, de posições equivocadas de um crítico sobre a despolitização 
de Rosa, ao afirmar que "a história é eliminada" em Grande sertão: veredas, estando eliminada, desta forma, a "dinamicidade do real". O virtuosismo de linguagem, qualidade incontestável da obra do escritor, serviria apenas para "separar a linguagem do homem". Em Meias-verdades no romance, no artigo "É...não é", a autora já havia respondido a essa acusação, quando afirma não ser Rosa o "escritor da denúncia social direta", por ser "o escritor da alegoria". No seu entender, a posição crítica de natureza partidária se mostrava insensível aos apelos do texto, configurados pelos erros cometidos na defesa da militância política do discurso literário: "As denúncias são sutis, espraiam-se pela narrativa, insertas na lei do sertão, na lei do mais forte."

Como reagiriam a essas ponderações as correntes da crítica contemporânea defensoras da voz das minorias e dos excluídos? Não resta dúvida de que a obra de Rosa tem servido de material importante para trabalhos de natureza histórica e política, cujos resultados revelam-se satisfatórios, embora sejam negligenciados componentes narrativos e de linguagem pela ênfase na análise temática. Seria desejável acenar para futuros leitores sobre o legado do papel de Dirce na tradição da crítica literária rosiana, em termos de uma leitura que congregue aspectos enunciativos e ingredientes de ordem temática. O jogo entre narrador/ interlocutor/leitor exige a observância de nuanças da enunciação crítica, observando-se o lugar da fala do sertanejo, o vínculo à oralidade, à experiência e à especulação, assim como o registro do interlocutor letrado, à margem da realidade do sertão. Reside aí a complexa articulação na obra entre os registros erudito e popular, fala e escrita, ficção e realidade:

Ao intérprete de Grande sertão: veredas, apresenta-se uma situação toda especial. O narrador, jagunço aposentado, que está de "range-rede" quando "se inventa gosto de especular ideia", propõe que a sua narrativa oral seja interpretada pelo visitante, que tem "carta de doutor" e a quem ele dita o texto. (...) Como se trata de interpretação do sertão brasileiro pelo sertanejo local e a ele se opõem as ideias preconcebidas do letrado que vem de fora para observá-lo, impõe-se a assimilação de atitudes culturais: "Não me assume o senhor por beócio. Uma coisa é pôr no papel ideias arranjadas, outra é lidar com país de pessoas de carne e de sangue, de mil e tantas misérias."

O empenho em divulgar e incentivar novas reflexões no âmbito da crítica deve-se, em grande parte, às atividades exercidas por Dirce no 
meio universitário e intelectual do país. Entre elas, destacam-se aquelas levadas a termo na década de 1980 e 90, como a organização de cinco Colóquios na UERJ, ocasião propícia para que se ampliassem as fronteiras disciplinares. Com vistas ao aprimoramento dos discursos de história social e de filosofia, possibilitou o diálogo entre pesquisadores nacionais e internacionais, redefinindo os caminhos da crítica literária, da literatura comparada e cultural.

No $2^{\circ}$. Colóquio, dedicado à discussão do conceito de "Interpretação", coube à ensaísta apresentação de um artigo no qual pontua e discute o termo, elegendo Machado e Rosa como intérpretes do Brasil. Justifica assim sua posição quanto ao igual reconhecimento do valor de representação social de pensadores e artistas, por desempenharem papel relevante na reflexão sobre história e cultura nacionais. Coloca-se ainda na defesa dos autores diante de afirmações errôneas de estudiosos de sua obra, revisitando, como argumentação de sua tese, a consagrada recepção crítica de ambos. Com o respaldo desses discursos e dos preceitos teóricos, sua contribuição para a avançada análise das obras conduz à elucidação de seu lugar no espaço político da crítica rosiana, sem radicalismos e conclusões extremas. A escolha de eminentes escritores de ficção como emblemáticos da cultura brasileira em distintos momentos efetua-se pela problematização do aspecto paradoxal das personagens, da presença do dialogismo como apelo à participação do outro e do "choque entre o homem e o mundo, entre o indivíduo e a sociedade". Apropriando-se do discurso alheio, reformulando-o e reinterpretando-o, a literatura expande o discurso comunitário e responde pelo descentramento de preceitos próprios ao senso comum. Por ser a obra de arte "um mosaico de textos alheios", o universo fabular de Rosa exerce, nas palavras da autora, a função de "operador compulsivo dessa heterogeneidade fragmentária." Interpretante dos textos por ele assimilados e deglutidos, inscreve a ficção na rede infinita de significações, por meio da qual os discursos desdobram-se e reinventam-se, impelidos pela força dos devires e da infinita interlocução dos leitores.

Interpretar a produção crítica de Dirce Côrtes Riedel poderia ser traduzida no gesto de apreço e consideração por quem dedicou toda a vida a narrar e glosar mensagens, muitas vezes de difícil entendimento, e a transmitir lições de solidariedade frente aos saberes e suas incertezas. A revisão da história da crítica no Brasil necessita ser incrementada pelo discurso acadêmico, na sua maioria ainda centrado na reprodução de teorias estrangeiras, em detrimento do quadro de representantes nacionais. 
Esta tarefa, ainda incipiente entre nós, elucidaria as razões dos equívocos de julgamento e incentivaria a revisão do lugar que o pensamento considerado periférico é capaz de ocupar na história das ideias.

\section{TO TELL IS TO GLOSS, TO LIVE IS TO TELL}

\section{ABSTRACT}

This article analyzes Dirce Côrtes Riedel's collaboration for Guimarães Rosa's critical reception, taking into account the publication of essays and books devoted to the author's work. It also adds the role of this scholar in the training of teachers and researchers from several universities in the country. KEYWORDS: Reception; critical; university.

\section{REFERÊNCIAS}

RIEDEL, Dirce Côrtes. Viver literatura- ensaios e artigos. Organização de Ana Cláudia Viegas. Rio de Janeiro: Eduerj, 2009.

RIEDEL, Dirce Côrtes. Meias-verdades no romance. Rio de Janeiro: Achiamé, 1980.

RIEDEL, Dirce Côrtes. Metáfora - o espelho de Machado de Assis. Rio de Janeiro: Francisco Alves, 1974.

RIEDEL, Dirce Côrtes. O tempo no romance machadiano. Rio de Janeiro: Editora Livraria São José, 1959.

RIEDEL, Dirce Côrtes. Tempo e metáfora em Machado de Assis. Rio de Janeiro: Eduerj, 2009.

Recebido em: 14 de outubro de 2016

Aceito em: 31 de outubro de 2016 